Historic, Archive Document

Do not assume content reflects current scientific knowledge, policies, or practices. 
. 


\section{VELVET BEANS} GROWN AND FOR SALE BY

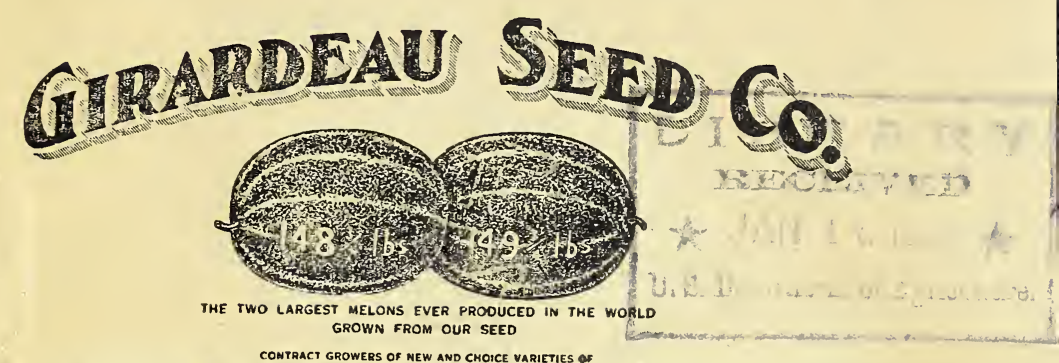

WATERMELON AND CANTALOUPE SEED

ALL QUOTAT UNS TRE MADE FOR IMMEDIATE ACCEPTANCE AND SUBJECT TO STOCK UNSOLD UPON RECEIPT OF ORDER W CASE OF SHORTAGE OR FAILURE OF CROPS, DELIVERY WILL BE MADE PRO-RATA TO EACH CONTRACT CUSTOMER ORDER

\section{MONTICELLO, FLA.}

Velvet Beans are probably the cheapest soil-improving crop, cost of seed considered, that can be put in. It really only requires about a peck of seed to the acre. They are usually planted in rows five feet apart, dropping the beans about a foot apart in the rows. They make a very rapid and enormous growth, and soon cover the land wherever they are sown. On account of their large and heavy growth, it is difficult to cure them as"a forage crop, and the best use is to let the vines and all be killed by frost and rot upon the ground before attempting to turn them under. Velvet Beans are also largely used in Florida and the extreme South as a cattle grazing and fattening crop, and with excellent and profitable results, and we believe that in this section they will also prove most desirable for this purpose. The cattle are turned into the velvet bean fields late in the fall, and thrive remarkably, grazing on the enormous mass of leaves and vines, and this is continued until late in the winter, with very satisfactory results. Write for prices.

\section{GIRARDEAU SEED COMPANY,}

Monticello, Fla. 


\subsection{He \\ ins in}

(Q) 2 atide

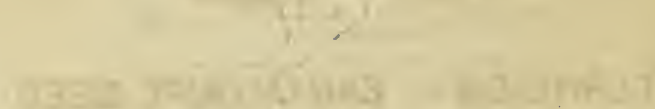

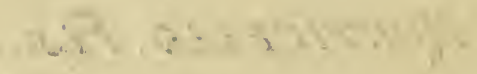
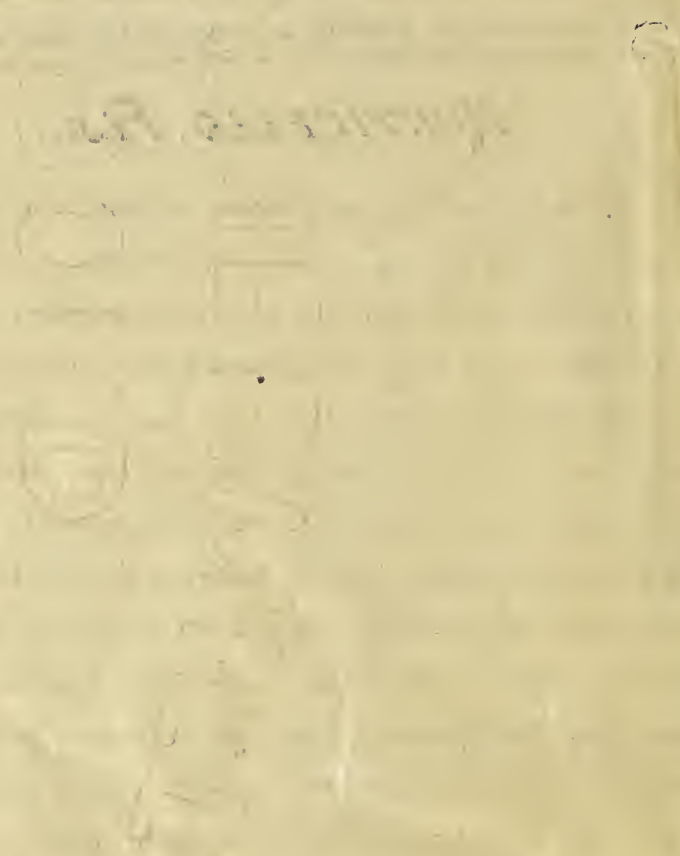

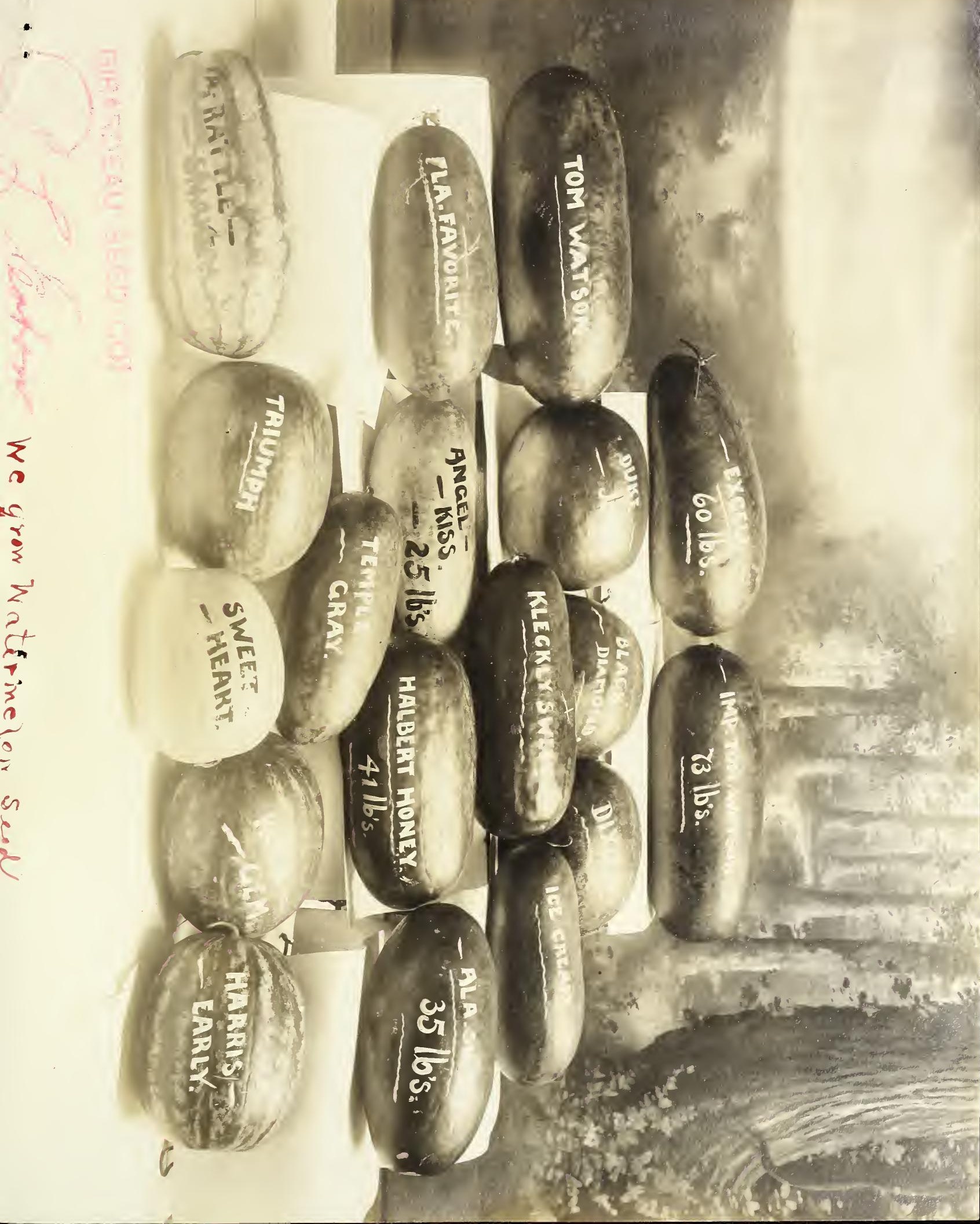


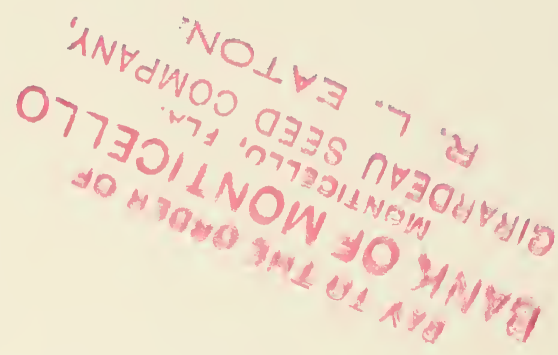

